\title{
Ultrasensitive electrical detection of protein using nanogap electrodes and nanoparticle-based DNA amplification
}

\author{
Tien-Li Chang ${ }^{\mathrm{a}}$, Chien-Ying Tsai ${ }^{\mathrm{b}}$, Chih-Chen Sun ${ }^{\mathrm{b}}$, Chun-Chi Chen ${ }^{\mathrm{c}}$, \\ Long-Sheng Kuo ${ }^{\mathrm{b}}$, Ping-Hei Chen ${ }^{\mathrm{b}, *}$ \\ ${ }^{a}$ Mechanical and Systems Research Laboratories, Industrial Technology Research Institute, Hsinchu 310, Taiwan \\ ${ }^{\mathrm{b}}$ Department of Mechanical Engineering, National Taiwan University, Taipei 106, Taiwan \\ ${ }^{\mathrm{c}}$ National Nano Device Laboratories, Hsinchu 300, Taiwan
}

Received 13 September 2006; received in revised form 5 December 2006; accepted 6 February 2007

Available online 14 February 2007

\begin{abstract}
The present study describes an ultrasensitive protein biochip that employs nanogap electrodes and self-assembled nanoparticles to electrically detect protein. A bio-barcode DNA technique amplifies the concentration of target antigen at least 100-fold. This technique requires the establishment of conjugate magnetic nanoparticles (MNPs) and gold nanoparticles (AuNPs) through binding between monoclonal antibodies (2B2), the target antigen, and polyclonal antibodies (GP). Both GP and capture ssDNA (single-strand DNA) bonds to bio-barcode ssDNA are immobilized on the surface of AuNPs. A denature process releases the bio-barcode ssDNAs into the solution, and a hybridization process establishes multilayer AuNPs over the gap surface between electrodes. Electric current through double-layer self-assembled AuNPs is much greater than that through self-assembled monolayer AuNPs. This significant increase in electric current provides evidence that the solution contains the target antigen. Results show that the protein biochip attains a sensitivity of up to $1 \mathrm{pg} / \mu \mathrm{L}$.
\end{abstract}

(C) 2007 Elsevier B.V. All rights reserved.

Keywords: Bio-barcode DNA detection; Electrical detection; Protein biochip; Magnetic nanoparticles; Gold nanoparticles; Self-assembly

\section{Introduction}

Researchers have extensively developed DNA chips for gene expression profiling and mutation mapping (Thomas et al., 1998) over the past decade. Since the activity of encoded proteins can directly manifest gene function (Emili and Cagney, 2000), scientists must develop a protein biochip that can identify target proteins and provide information useful to many medical applications, including diagnostics and drug discovery. The basic construction of such a protein chip is somewhat similar to a DNA chip because it has a glass, plastic and silicon oxide surface immobilized with biomolecules. These biomolecules can be DNA or antibodies designed to capture protein. This approach has emerged as an exciting technology for ana-

\footnotetext{
* Corresponding author at: Mechanical Engineering Department, National Taiwan University, No. 1, Roosevelt Road Sec. 4, Taipei 10617, Taiwan. Tel.: +8862 33662689; fax: +8862 23670781/31755.

E-mail addresses: d91522011@ntu.edu.tw (T.-L. Chang), phchen@ntu.edu.tw (P.-H. Chen).
}

lyzing antibody-antigen, protein-protein, protein-nucleic-acid, protein-lipid, and protein-small-molecule or enzyme-substrate interactions.

Recent control processes for infectious diseases such as avian influenza, i.e., bird flu, prove that protein chips will soon become a powerful tool to identify specific proteins taken from patient samples. Protein detection methods are generally fluorescencebased (Walt, 2000) or electrochemical-based (Kojima et al., 2003). The general format of many test samples is analogous to the sandwich assays method. A sensing surface is immobilized with a bioconjugate such as an antibody which is capable of selectively binding the desired target from a solution. Completing the sandwich with a second selective bioconjugate allows detection when the sandwich is tagged with a particle.

Of all the diagnostic detection methods involving antibodyantigen complex forming on a solid phase, enzyme-linked immunosorbent assay (ELISA) is one of the most popular methods for disease detection owing to its simplicity and high sensitivity (Takasaki et al., 1981; Gosling, 1990). However, the detection of well-characterized antibody-antigen reaction relies 
on the enzyme catalytic activity of an appropriate transparent substrate to produce a colored product. The intensity of this product is then measured by an expensive optical device. Experienced operators must perform the ELISA method to obtain accurate results. Since the application of a protein chip plays an essential role in molecular biological analysis (Arenkov et al., 2000; Kelvin, 2001), the development of simple protein chips has become very important in recent years.

Biomolecule-functional magnetic particles $\left(\mathrm{Fe}_{3} \mathrm{O}_{4}\right)$ have been extensively applied in various bioelectronic applications. Wang et al. (2001) reported electrochemical detection of DNA using magnetic particles for separation and concentration of target DNA. An interesting approach for the magneto-controlled amplified detection of DNA or protein can also be developed (Nam et al., 2004). Recently, Mirkin's group used a novel bio-barcode amplification (BCA) technique to amplify the signal in the protein detection approach (Nam et al., 2003). The BCA technique utilizes gold nanoparticles (AuNPs), magnetic microparticles and barcode single-strand DNA (ssDNA). This approach also uses a silver enhancement technique to amplify optical signal and improve detection sensitivity. However, electrical detection of protein is superior to optical detection methods due to easier operation and data analysis. The present study performs ultrasensitive detection of protein by integrating an electrical approach utilizing MNPs and bio-barcode DNA to improve electrical current through nanogap electrodes from extremely low concentrations of target DNA.

\section{Experimental}

The protein on-chip sensing system includes nanogap electrodes fabricated by electron-beam lithography, magnetic nanoparticle-based genome extraction (i.e., BCA method), and self-assembled multilayer AuNPs.

\subsection{Nanogap electrode fabrication process}

A p-type $\mathrm{Si}(100)$ wafer was covered with $2000 \AA$ A thick silicon dioxide film by the plasma enhanced chemical vapor deposition (PECVD) method. Resist with a $7000 \AA$ thickness was then spincoated onto the silicon dioxide and the electrodes with $300 \mathrm{~nm}$ gaps patterned by electron-beam lithography (Leica Weprint model-200 stepper, Jena, Germany). A $50 \AA$ titanium film was sputtered for adhesion purposes prior to deposition of $350 \AA$ gold film. Finally, acetone solvent was used to remove the resist for $2 \mathrm{~h}$.

\subsection{Preparation of gold nanoparticles}

Dispersed AuNPs were prepared by reducing aqueous hydrogen tetrachloroaurate $\left(\mathrm{HAuCl}_{4}\right)$ with trisodium citrate and tannic acid using the chemical reduction method (Hayat, 1989). A solution of $1 \mathrm{mg} \mathrm{HAuCl}_{4}$ in $80 \mathrm{~mL}$ distilled water and a solution of $0.05 \mathrm{mg}$ trisodium citrate and $0.01 \mathrm{mg}$ tannic acid in $20 \mathrm{~mL}$ distilled water were both prepared. Both solutions were poured into a container and the mixed solution was heated to $60^{\circ} \mathrm{C}$ with vigorous stirring. The heater was immediately turned off when mixed solution color changed to crimson. The solution was held at $60^{\circ} \mathrm{C}$ for approximately $3 \mathrm{~min}$ before the mixed solution changed color. Colloidal gold nanoparticles formed in the solution after it cooled to room temperature. A Hitachi U3310 UV-vis spectrometer and a high-resolution transmission electronic microscope were used to determine the size of AuNPs in the AuNP solution. The UV-vis absorption spectrum of AuNPs solution showed a strong surface plasma resonance at a wavelength of $523 \mathrm{~nm}$. The HR-TEM micrograph revealed that the diameter of monodispersed Au colloidal particles ranged from $12 \pm 4 \mathrm{~nm}$. Notably, the size of AuNPs in the solution can be varied by changing the concentration of trisodium citrate in the aqueous solution.

\subsection{Magnetic nanoparticle preparation}

Magnetic nanoparticles (MNPs) were synthesized using the chemical coprecipitation technique (Huang et al., 2003; Sun et al., 2004). The first step of the preparation process was selection of the materials $\mathrm{FeCl}_{2}, \mathrm{FeCl}_{3}$, and $\mathrm{NH}_{4} \mathrm{OH}$. Then the $\mathrm{FeCl}_{2}$ and $\mathrm{FeCl}_{3}$ solutions were weighed at $9.02 \mathrm{~g} \mathrm{FeCl}_{2} \bullet 4 \mathrm{H}_{2} \mathrm{O}$ and $3.32 \mathrm{~g}$ $\mathrm{FeCl}_{3}{ }^{\bullet} 6 \mathrm{H}_{2} \mathrm{O}$, respectively. After the materials were weighed, $34 \mathrm{~mL}$ of distilled water was added to each solution and stirred for $15 \mathrm{~min}$ to ensure that all particles were dissolved in the solution. All three solutions were then mixed in a beaker and stirred for $30 \mathrm{~min}$ at $500 \mathrm{rpm}$. Aqueous $30 \mathrm{wt}$.\% solution $\mathrm{NH}_{4} \mathrm{OH}$ was added to the mixture at a control $\mathrm{pH}$ value of $10-11.8$. After decantation, suspensions were heated at $80^{\circ} \mathrm{C}$ for $1 \mathrm{~h}$ under continuous mixing and separated by centrifuging three times in distilled water to remove impurities.

A vibration sample magnetometer (VSM, model: 7300, Lakeshore) revealed the superparamagnetic character of the hysteresis curve in the MNPs solution. The MNPs solution was measured by VSM at $25^{\circ} \mathrm{C}$ and $\pm 13,500$ Oe applied magnetic field. The increasing and decreasing applied field process was repeated five times to produce the hysteresis curve and examine nanofluid magnetic properties. According to the HRTEM micrograph, the magnetic nanoparticles are approximately spherical and average $27 \pm 4 \mathrm{~nm}$ in size.

\subsection{Conjugation of barcode DNA with functional magnetic nanoparticles}

The most important step in this experiment is collecting barcode DNA with functional MNPs. In the BCA method, the biochip detects barcode DNA rather than the target antigen. To detect target antigen in the sample by the barcode DNA amplification approach, two set of biomolecules were prepared. One set of biomolecules contained three proteins (monoclonal antibody (2B2), the target antigen, and polyclonal antibodies (GP)), where the antigen can specifically bind to both antibodies. The second set of biomolecules contained three single-strand DNAs (capture DNA (CDNA), barcode DNA, and probe DNA (PDNA)). The barcode DNA is complementary to both CDNA and PDNA. The sequences of CDNA, barcode DNA, and PDNA are $3^{\prime}$-HSA10-CCT AAT AAC-5', 5'-GGA TTA TTG TTA AAT ATT GAT AAG GAT-3' and $3^{\prime}$-TTA TAA CTA TTC CTA-A10-SH- 
$5^{\prime}$, respectively. All biomolecule samples including protein and DNA in this study were obtained from General Biological Corp. (Hsinchu, Taiwan) and Proligo Inc. (Singapore), respectively.

Fig. 1(A)-(D) shows the detective concept of protein, which can be stated as follows. The biomolecule materials for the BCA protein chip can be prepared with one DNA component and one protein component. First, $1 \mathrm{~mL}$ MNPs was mixed with $2 \mathrm{~mL}$ of $0.3 \mathrm{M}$ phosphate-buffered saline (PBS) buffer. The solution was then functionalized with $2.5 \mathrm{~mL}$ of $0.3 \mathrm{mg} / \mathrm{mL} \mathrm{HCV} \mathrm{2B2}$

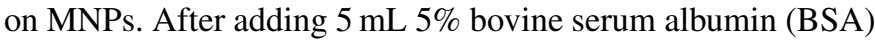
to the aqueous solution from the previous step and incubating at $37^{\circ} \mathrm{C}$ for $2 \mathrm{~h}$, MNPs attached to $2 \mathrm{~B} 2$ can be obtained. Target $\mathrm{HCV}$ antigen solution was also prepared to hybridize with 2B2 on MNPs. In this study six different concentrations of target antigen $(10 \mathrm{ng} / \mu \mathrm{L}, 1 \mathrm{ng} / \mu \mathrm{L}, 100 \mathrm{pg} / \mu \mathrm{L}, 10 \mathrm{pg} / \mu \mathrm{L}, 1 \mathrm{pg} / \mu \mathrm{L}$, $100 \mathrm{fg} / \mu \mathrm{L})$ solutions $(40 \mu \mathrm{L})$ were separately mixed with a $40 \mu \mathrm{L}$ solution of functionalized MNPs with $2 \mathrm{~B} 2$ at $37^{\circ} \mathrm{C}$ for $2 \mathrm{~h}$. With HCV antigen in the sample solution, gold nanoparticles (AuNPs) with polyclonal antibodies and barcode ssDNA were bound with magnetic nanoparticles (MNPs) with monoclonal antibodies through a sandwich binding between polyclonal antibodies, target HCV antigen, and monoclonal antibody. Since MNPs have superparamagnetic properties, the AuNP-MNP conjugates can be held by a $6000 \mathrm{G}$ permanent magnet and cannot be washed away by a $0.3 \mathrm{M}$ PBS buffer solution with a volume of $100 \mu \mathrm{L}$. If the sample solution contains no target $\mathrm{HCV}$ antigen, the MNPs and AuNPs binding does not occur. Consequently, the PBS buffer solution washes away all the unbound AuNPs with barcode DNA. The biochip is then washed with $100 \mu \mathrm{L}$ of $0.3 \mathrm{M}$ PBS buffer solution three times at room temperature. The sodium phosphate buffer solution is kept at a $\mathrm{pH}$ value of 7.4 so AuNPs cannot functionalize with barcode DNA and GP. An appropriate $\mathrm{pH}$ value (7.1-8.3) is helpful in binding antibodies to AuNPs. The GP $(200 \mu \mathrm{L}, 10 \mu \mathrm{g})$ solution was mixed with AuNPs aqueous solution $(1 \mathrm{~mL})$ and incubated at $37^{\circ} \mathrm{C}$ for $20 \mathrm{~min}$. After this step, $2 \mathrm{~mL}$ of $5 \mathrm{M} \mathrm{NaCl}$ were added to the solution to produce conjugate AuNPs and GP. A $0.3 \mathrm{~mL} 10 \%$ BSA and CDNA $(100 \mu \mathrm{L}, 6 \mu \mathrm{M})$ with barcode DNA $(100 \mu \mathrm{L}$, $6 \mu \mathrm{M})$ hybridization attached to AuNPs $(100 \mu \mathrm{L})$ were mixed together and incubated at $37^{\circ} \mathrm{C}$ for $2 \mathrm{~h}$ to stabilize the AuNPs. The solution was then centrifuged at $20,000 \mathrm{rpm}$ for $2 \mathrm{~h}$ at $4{ }^{\circ} \mathrm{C}$ to remove supernatant was removed. Next, $\mathrm{NaCl}(1.5 \mathrm{~mL}, 0.1 \mathrm{M})$ with $0.3 \%$ BSA was added to the solution again. An additional $12 \mathrm{~mL}$ of $0.1 \mathrm{M} \mathrm{NaCl}$ with $0.01 \mathrm{M}$ PBS buffer was added to the solution to obtain a $\mathrm{pH}$ value of 7.4. Following these steps, MNP-2B2 conjugate, GP-AuNP-DNA conjugate, and target antigen were specifically bound. The unbound AuNP-DNA and $\mathrm{MNP}$-protein conjugate can be separated by a $6000 \mathrm{G}$ permanent magnet and 0.3 M PBS buffer after three washings. Washing with a $0.1 \mathrm{M}$ PBS buffer for $5 \mathrm{~min}$ at room temperature dehybridizes a large ratio of barcode DNA for target antigen amplification from AuNP-DNA and MNP-protein conjugate. Using the mag-

(A)

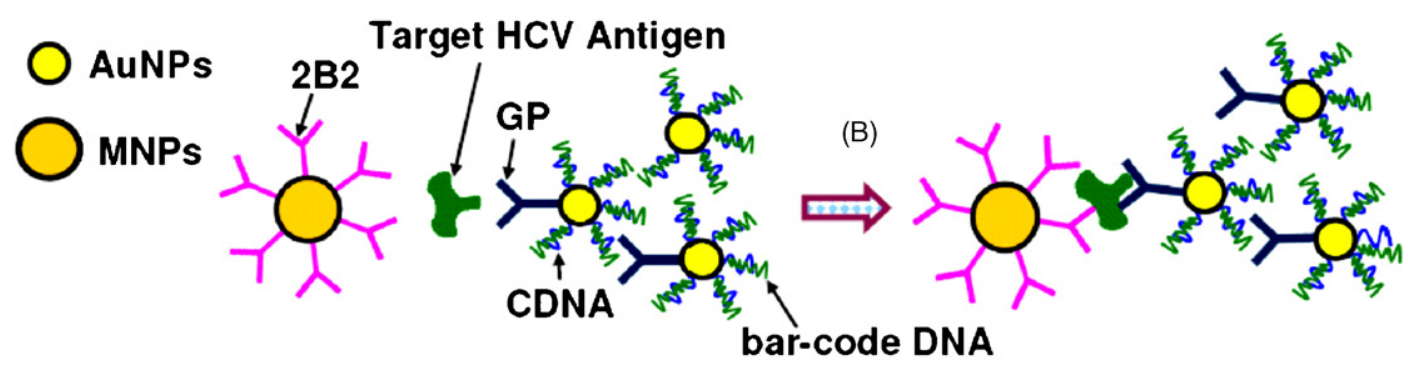

(C)

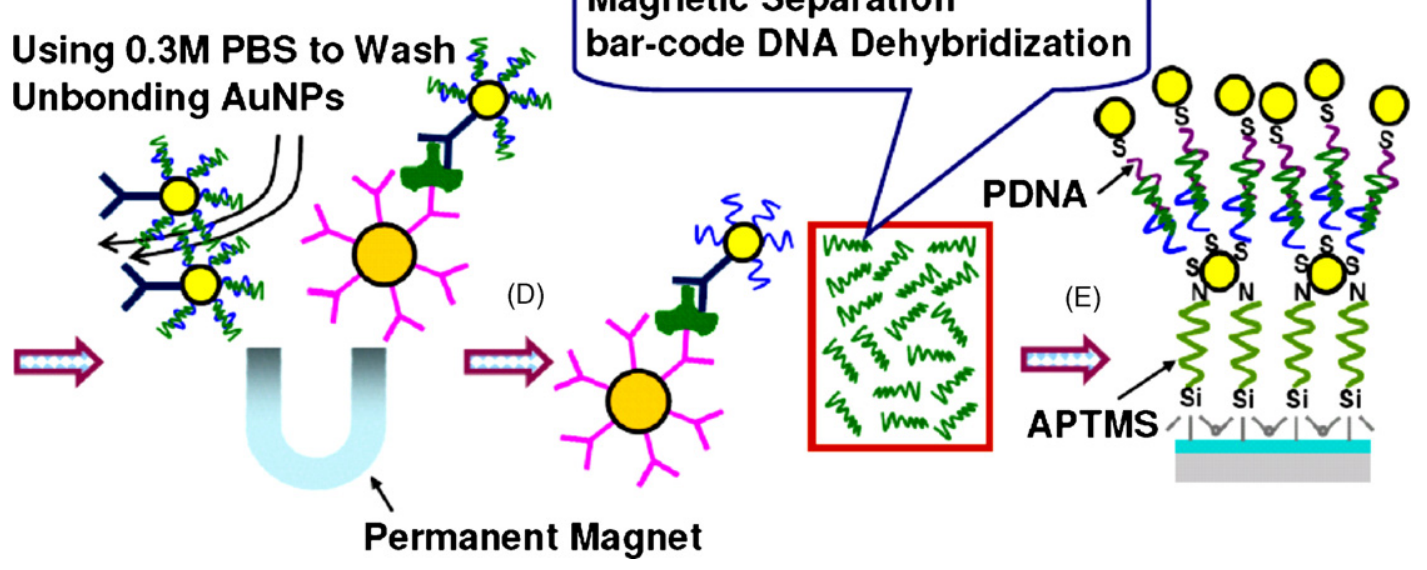

Fig. 1. The procedure for protein molecule measurement based on the attachment of barcode DNA detection uses nanogap electrodes. (A) 2B2 of MNP-protein and GP of AuNP-DNA conjugates. (B) Specific binding between 2B2 of MNP-protein conjugate, GP of AuNP-DNA conjugate, and target antigen. (C) Separation between unbound AuNP-DNA conjugate and MNP-protein conjugate with a $6000 \mathrm{G}$ permanent magnet. (D) Collection of barcode DNA after denature between CDNA and barcode DNA of three-component MNP-protein conjugate. (E) Establishment of second layer of AuNPs with hybridization between barcode, PDNA, and CDNA that is already immobilized on the first layer of AuNPs. 
(A)

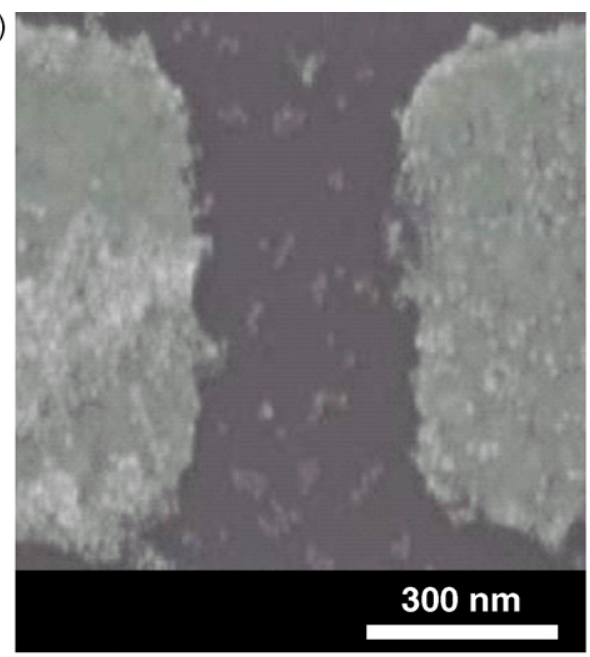

(B)

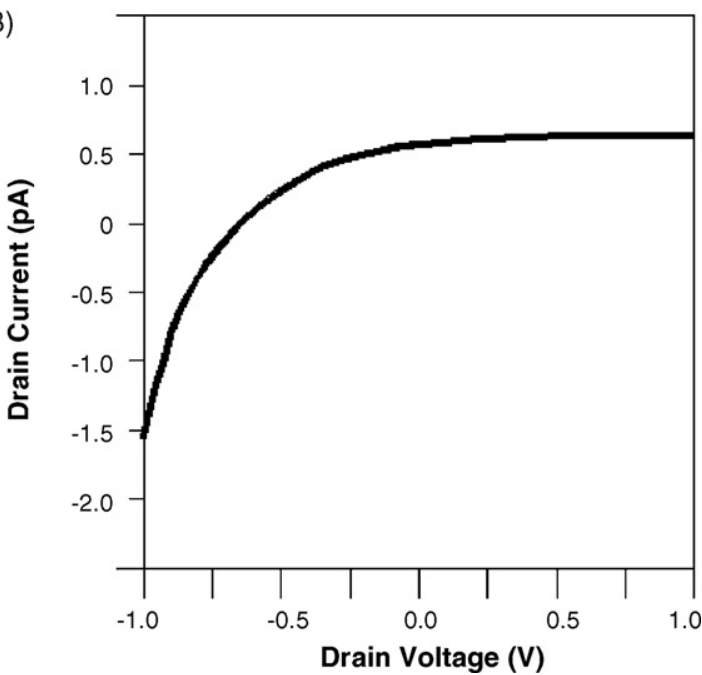

Fig. 2. (A) FE-SEM image and (B) $I-V$ curve for the AuNPs monolayer immobilized on the silicon dioxide substrate between the nanogap gold electrodes. The outset detection study revealed that the substrate surface can be modified by chemical compound 3-aminopropyltrimethoxysilane (ATPMS) to bind AuNPs for $10 \mathrm{~min}$.

netic separator, the barcode DNA is released from the hybridized AuNPs-DNA and MNPs-protein aqueous solution. This separation can be quickly identified with standard DNA detection methodologies.

\subsection{Immobilization of thiol-modified DNA probes and} self-assembly of AuNP multilayer onto substrate gold surfaces

Before assembly with the bio-barcode DNA on-chip sensing system, the substrate was cleaned by immersion in 1:1 concentrated $\mathrm{HCl}: \mathrm{MeOH}$ for $30 \mathrm{~min}$, followed by rinsing with distilled water. The substrate was then immersed in concentrated $\mathrm{H}_{2} \mathrm{SO}_{4}$ for $5 \mathrm{~min}$ and again rinsed with distilled water. The self-assembled monolayer of AuNPs was established on the silicon dioxide surface using $1 \mathrm{mM} 3$-aminopropyltrimethoxysilane (APTMS) of dimethyl sulphoxide (DMSO) solution for $2 \mathrm{~h}$ at room temperature. The substrate was then rinsed with DMSO and dried under $\mathrm{N}_{2}$. One end of the APTMS compound was to silanize the group substrate surface while the amine group at the other end was used to bind the AuNPs. The principle BCA protein detection is similar to BCA DNA detection. The target antigen is barcode DNA, thanks to this study for the bio-barcode amplification technique which can measure barcode DNA rather than target antigens. Barcode DNA substitutes for target antigens can be detected by AuNP, MNP, and DNA hybridization. Fig. 1(E) shows the self-assembled AuNPs and DNA hybridization. Although a target $\mathrm{HCV}$ antigen is intended for detection in the sample solution, barcode DNA is used instead of HCV antigen to establish multilayer gold nanoparticles for electrical detection in later $I-V$ curve measurements. The procedure for establishing multilayer gold nanoparticles using barcode DNA is the same as for detecting target DNA via Tsai et al. (2005a,b). Identifying specific barcode DNA requires a check of any mismatch in the hybridization among ssDNAs. The chip is therefore washed with a $0.01 \mathrm{M}$ PBS buffer at room temperature (Park et al., 2002). If DNA hybridization is not fully complementary,
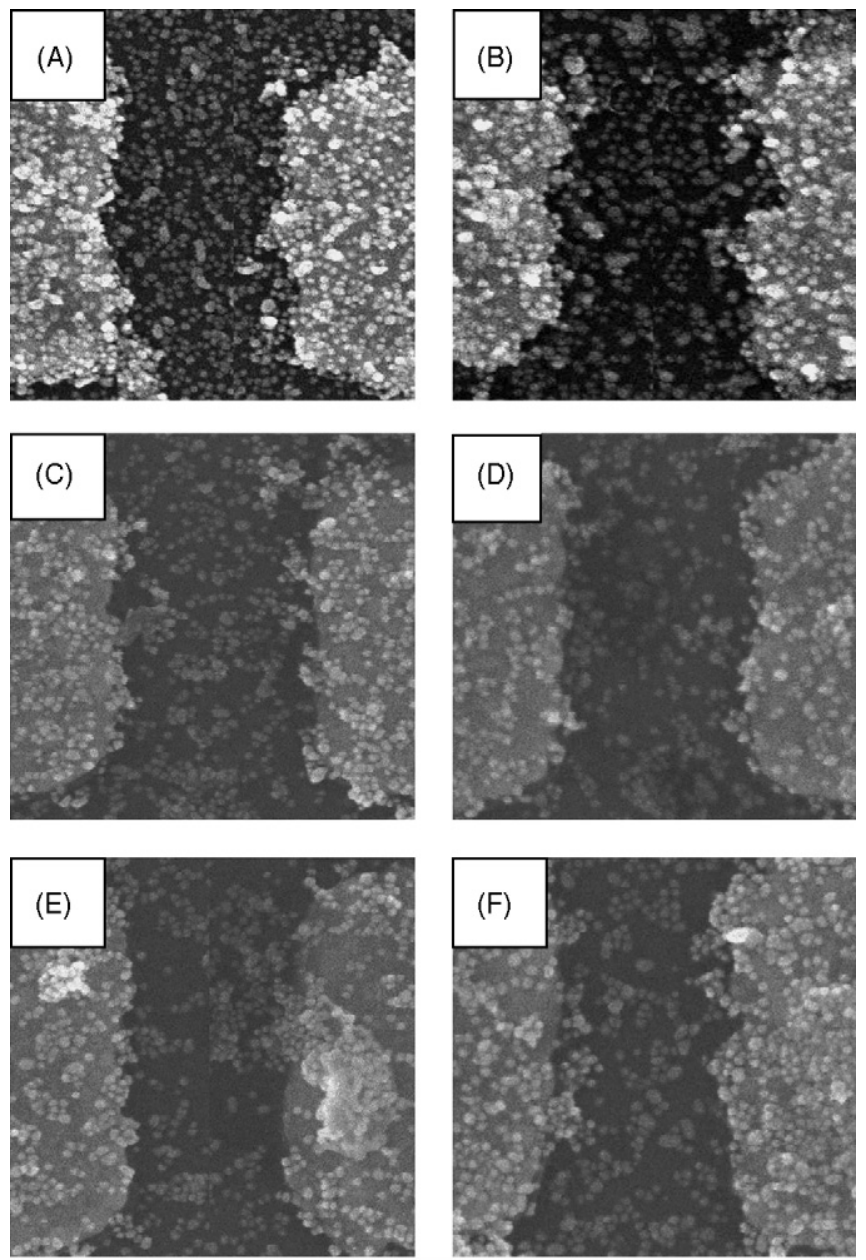

$300 \mathrm{~nm}$

Fig. 3. FE-SEM images of the AuNPs multilayer with bio-barcode DNA amplification for target $\mathrm{HCV}$ antigen concentrations at: (A) $10 \mathrm{ng} / \mu \mathrm{L}$, (B) $1 \mathrm{ng} / \mu \mathrm{L}$, (C) $100 \mathrm{pg} / \mu \mathrm{L}$, (D) $10 \mathrm{pg} / \mu \mathrm{L}$, (E) $1 \mathrm{pg} / \mu \mathrm{L}$ and (F) $100 \mathrm{fg} / \mu \mathrm{L}$ for the first specific binding between $2 \mathrm{~B} 2$, GP, and $\mathrm{HCV}$ antigen. 
the top layer of AuNPs is washed away. Finally, the measurable $I-V$ curves of barcode DNA can be identified by the specific binding among proteins biomolecule reaction using nanogap electrodes and the self-assembled multilayer of nanoparticles. An electric current could be obtained in this study without any application of the silver enhancement approach for further signal amplification.

\section{Results and discussion}

This study develops an ultrasensitive electrical protein sensor, an electrical ligand-receptor interaction detection method, which greatly increases the potential of integrated biosensors in complex biological media. Target HCV (hepatitis C virus) antigen is obtained from mouse serum samples. The on-chip sensing system layout has identical $5 \times 5$ chips and each chip has $5 \times 5$ nanogap gold electrodes for a total of 625 electrode pairs on each wafer. Each chip has 25 pair of electrodes to measure 25 spots.

Fig. 2(A) shows the field-emission scanning electron microscopy (FE-SEM: JEOL, JSM-6500F) image of the fabricated $300 \mathrm{~nm}$ nanogap biochip surface with monolayer AuNPs. Fig. 2(B) shows the $I-V$ curve of monolayer AuNPs. Without the monolayer AuNPs, the current through gold electrodes is lower than $50 \mathrm{fA}$. The AuNPs are very uniformly distributed over the gap surface between two gold electrodes. When biomolecular treatment is absent, only the sheath current is detectable. The AuNPs function as many small islands bridging the electrode nanogap. With a bias voltage from $-1 \mathrm{~V}$ to $1 \mathrm{~V}$ using a HP 4156 precision semiconductor parameter analyzer at room temperature, the $I-V$ characteristics are consistent.

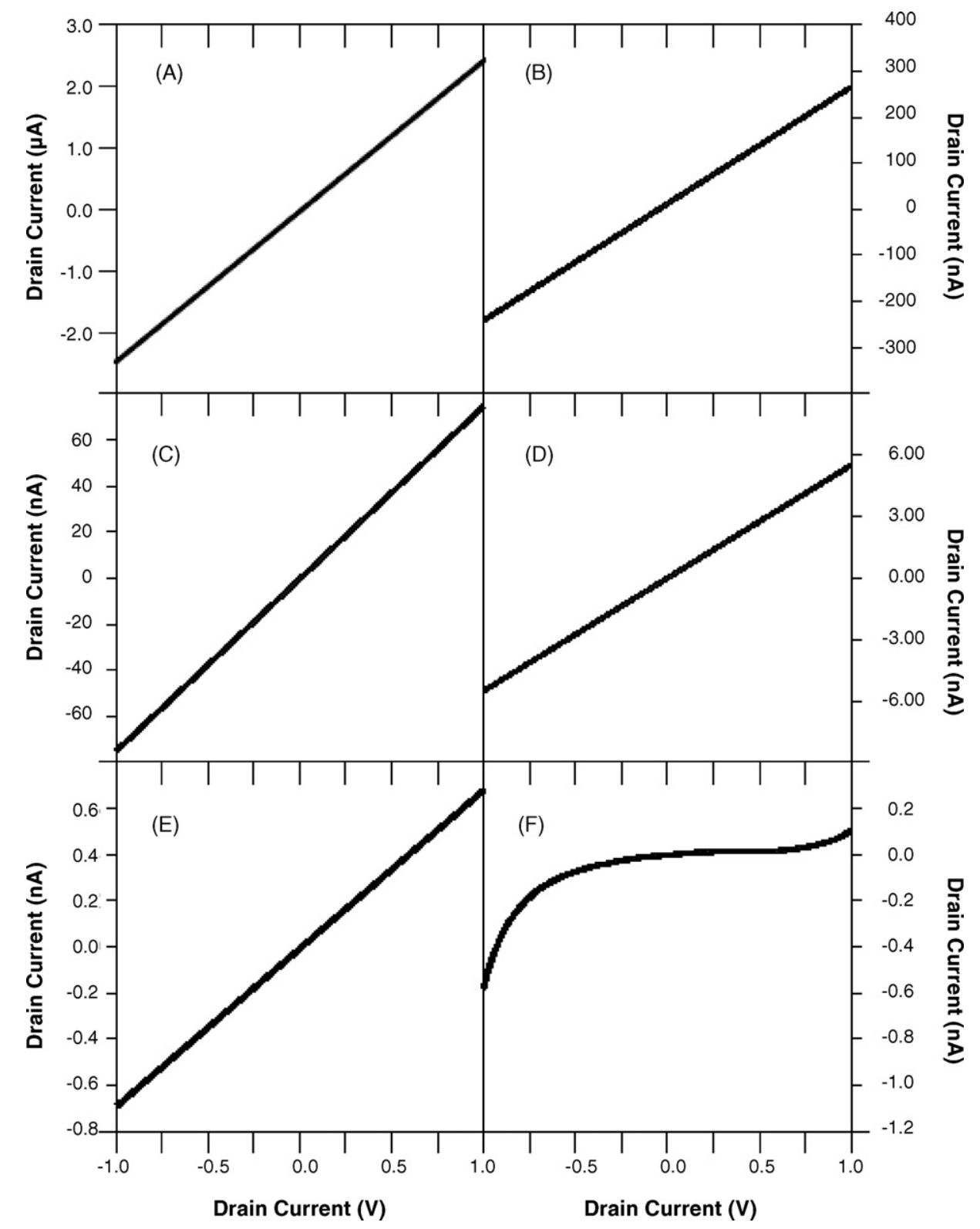

Fig. 4. $I-V$ curves of multilayer AuNPs at different $\mathrm{HCV}$ antigen concentrations with barcode DNA amplification: (A) $10 \mathrm{ng} / \mu \mathrm{L},(\mathrm{B}) 1 \mathrm{ng} / \mu \mathrm{L},(\mathrm{C}) 100 \mathrm{pg} / \mu \mathrm{L},(\mathrm{D})$ $10 \mathrm{pg} / \mu \mathrm{L},(\mathrm{E}) 1 \mathrm{pg} / \mu \mathrm{L}$ and $(\mathrm{F}) 100 \mathrm{fg} / \mu \mathrm{L}$. Each value is an average of 25 repetitions. 
The AuNPs can be randomly distributed on the $\mathrm{SiO}_{2}$ surface. For experiments on a single tested condition, $I-V$ measurements are taken from 25 measuring spots on one biochip. The FE-SEM micrograph was randomly selected from one measuring spot. Fig. 3(A)-(F) shows FE-SEM images of self-assembled multilayer AuNPs established through the hybridization of PDNA, CDNA, barcode DNA and AuNP conjugate at six different concentrations of target $\mathrm{HCV}$ antigen i.e., $10 \mathrm{ng} / \mu \mathrm{L}, 1 \mathrm{ng} / \mu \mathrm{L}, 100 \mathrm{pg} / \mu \mathrm{L}, 10 \mathrm{pg} / \mu \mathrm{L}, 1 \mathrm{pg} / \mu \mathrm{L}$ and $100 \mathrm{fg} / \mu \mathrm{L}$. The particle density of AuNPs over the nanogap surface increases as the concentration of $\mathrm{HCV}$ antigen increases. Fig. 3(A) $-(\mathrm{F})$ shows that the average densities of the particles are $\sim 3590$ particles $/ \mu \mathrm{m}^{2}, \sim 2750$ particles $/ \mu \mathrm{m}^{2}, \sim 2450$ particles $/ \mu \mathrm{m}^{2}, \sim 1400$ particles $/ \mu \mathrm{m}^{2}, \sim 1250$ particles $/ \mu \mathrm{m}^{2}$, and $\sim 1050$ particles $/ \mu \mathrm{m}^{2}$, respectively. Consequently, the distance between neighboring AuNPs decreases as the concentration of $\mathrm{HCV}$ antigen increases. Fig. 4 shows the $I-V$ curves of multilayer AuNPs with the electrical detection and BCA methods in nanogap devices at six different concentrations of $\mathrm{HCV}$ antigen. In these figures, the electric current increases with the applied voltage over the electrodes. In addition, the electric current through multilayer AuNPs increases with the concentration of HCV antigen at a fixed applied voltage (Fig. 4(A)-(E)). The $I-V$ results clearly obey Ohm's law, as is evident from the linear curves in the measurement. These results not only strengthen the electrical signal, but also help solve the problem of negative differential resistance when the target antigen is in low concentration. Fig. 4(F) shows that Schottky barrier behavior occurs in the $I-V$ curves. The electrical signal exhibits a low-bias conductance for a nanogap device followed by a nonlinear increase in current at a high bias voltage. The low current phenomenon $(<50 \mathrm{fA})$ occurs around $0 \mathrm{~V}$ when the applied electric voltage decreases or increases. Although the measured $I-V$ curve at a target antigen concentration of $100 \mathrm{fg} / \mu \mathrm{L}$ is like the electrical signal of monolayer self-assembled AuNPs, it still has greater electric current than that in Fig. 2(B). This current demonstrates the detection in this concentration that belongs to the BCA amplification method result. It is worth noting that the self-assembled multilayer AuNPs are established through the hybridization of barcode DNA, PDNA, and CDNA. The particle count of nanoparticles per unit area depends on the concentration of barcode DNA. Higher concentration of barcode DNA creates denser gold nanoparticle distribution over the gap surface between electrodes. Note that the concentration of barcode DNA increases with the concentration of target HCV antigen through a barcode DNA amplification process. Further, CDNA was already immobilized on the first layer of gold nanoparticles before hybridization of barcode DNA, PDNA, and CDNA takes place.

In Fig. 5, current signals histograms from three different target $\mathrm{HCV}$ antigen concentrations $(10 \mathrm{ng} / \mu \mathrm{L}, 1 \mathrm{ng} / \mu \mathrm{L}$, $100 \mathrm{pg} / \mu \mathrm{L}$ ) prove clearly that the BCA method can obtain much greater electric current through self-assembled AuNPs than methods without BCA at all three concentrations. For each protein molecule, the measurement can be repeated at least 25 times. The error bars indicate reproducibility for experimental measurements on each protein molecule. The variation of measured

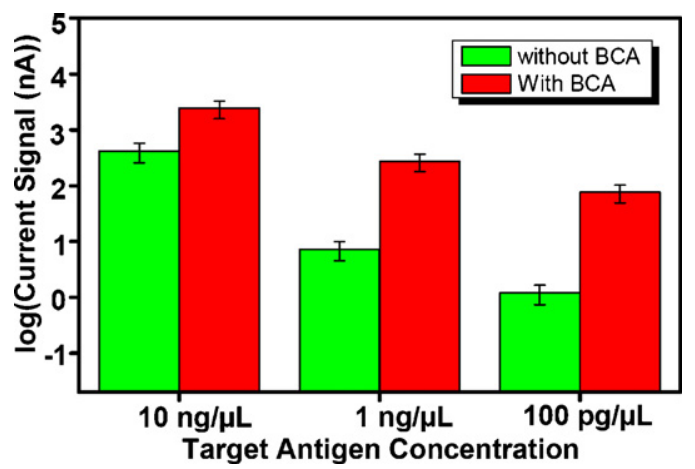

Fig. 5. Current signal of multilayer self-assembly layered AuNPs over a $300 \mathrm{~nm}$ nanogap in studies with and without BCA at target HCV antigen concentrations from $10 \mathrm{ng} / \mu \mathrm{L}$ to $100 \mathrm{pg} / \mu \mathrm{L}$.

currents is less than $25 \%$. Electrical detection without the BCA method is used to detect antigen-antibody complexes utilizing self-assembled multilayer AuNPs. The 2B2 is immobilized on the top surface of the first layer of AuNPs. The second layer of AuNPs is formed through specific binding of target antigen, 2B2, and conjugate of AuNP-GP. Different concentrations of target antigen conjugated between AuNP-GP and AuNP-2B2 require incubation for $30 \mathrm{~min}$ at $37^{\circ} \mathrm{C}$. After the chips are rinsed in 0.1 M PBS buffer three times, the electrical behavior of the target antigen can be measured between nanogap electrodes. These comparison results show that the problem of electrical detection of protein can be solved effectively by the BCA method owing to its complicated protein molecule. The amplified current signals decrease the noise signal and display approximately straight lines. The signals of electrical BCA detection obey Ohm's law, implying that they have great potential to play a key role in integrated diagnostic sensing chips.

Fig. 6 shows an electric resistance dependence of multilayer AuNPs at five concentrations of target $\mathrm{HCV}$ antigen ranging from $10 \mathrm{ng} / \mu \mathrm{L}$ to $1 \mathrm{pg} / \mu \mathrm{L}$ using electrical BCA detection methodology. The electric resistance of self-assembled multilayer AuNPs at $\mathrm{HCV}$ antigen concentration of $100 \mathrm{fg} / \mu \mathrm{L}$ cannot be considered because of its nonlinear $I-V$ curve. The repro-

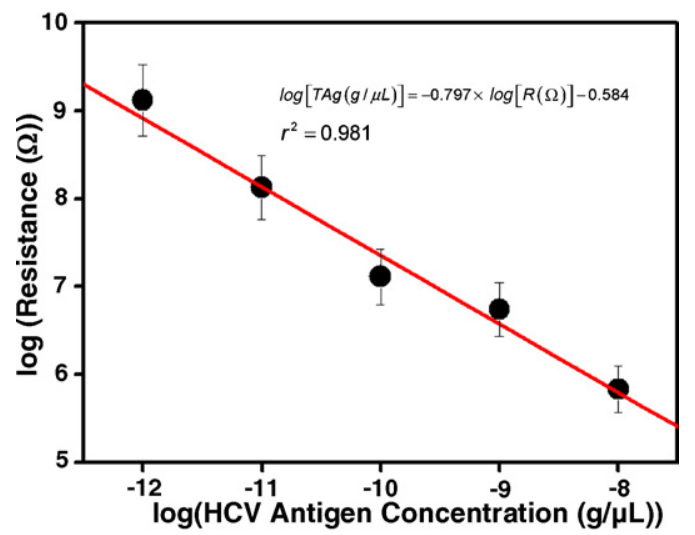

Fig. 6. Measured results of electric resistance of self-assembled multilayer AuNPs at HCV antigen concentrations from $10 \mathrm{ng} / \mu \mathrm{L}$ to $1 \mathrm{pg} / \mu \mathrm{L}$ using BCA amplification. Electric resistance as a function of the target $\mathrm{HCV}$ antigen concentration illustrates a linear correlation in the general behavior of BCA experimental data. 
ducibility of experimental results is checked by performing 25 different tests under the same test conditions. The error bars indicate good reproducibility of the present nanogap sensing system. The following diagram estimates the correlation between target $\mathrm{HCV}$ antigen concentration $\mathrm{TAg}(\mathrm{g} / \mu \mathrm{L})$ and electric resistance, $R(\Omega)$, defined as:

$\log [\operatorname{TAg}(\mathrm{g} / \mu \mathrm{L})]=-0.797 \log [R(\Omega)]-0.584$

The correlation equations vary the resistance of self-assembled multilayer AuNPs with concentration of target $\mathrm{HCV}$ antigen at room temperature.

\section{Conclusion}

In summary, a novel electrical method for protein detection is developed by combining a nanogap device, self-assembled multilayer AuNPs, and magnetic nanoparticle probes functionalized with bio-barcode receptors to detect low concentrations of target $\mathrm{HCV}$ antigen. With the application of nanogap electrodes, electric currents through self-assembled AuNPs between electrodes can be easily obtained without silver enhancement. This on-chip protein detection technique has the advantage of using only a tiny amount of protein in each assay, and also excludes the need of complicated conjugation chemistry for attaching DNA to the labeling antibody. Measured $I-V$ curves with the BCA method show linear behavior that follows Ohm's law. The electric resistances obtained from linear $I-V$ curves can serve as read-out signals for determining $\mathrm{HCV}$ antigen concentrations. Results indicate that the detection limit of the protein biochip is $1 \mathrm{pg} / \mu \mathrm{L}$.

\section{Acknowledgements}

The authors wish to thank the National Nano Device Laboratories (NDL) for providing experimental facilities. We deeply appreciate the financial support offered by the National Science Council (NSC) of Taiwan, Republic of China under contract NSC 94-2212-E-002-049.

\section{References}

Arenkov, P., Kukhtin, A., Gemmell, A., Voloshchuk, S., Chupeeva, V., Mirzabekov, A., 2000. Anal. Biochem. 278, 123-131.

Emili, A.Q., Cagney, G., 2000. Nat. Biotechnol. 18, 393-397.

Gosling, J.P., 1990. Clin. Chem. 278, 1408-1427.

Hayat, M.A., 1989. Colloidal Gold: Principles, Methods and Applications, vol. 1. Academic Press, San Diego.

Huang, S.H., Liao, M.H., Chen, D.H., 2003. Biotechnol. Prog. 19, 1095-1100.

Kelvin, H.L., 2001. Trends Biotechnol. 19, 217-222.

Kojima, K., Hiratsuka, A., Suzuki, H., Yano, K., Ikebukuro, K., Karube, I., 2003. Anal. Chem. 75, 1116-1122.

Nam, J.M., Stoeva, S.I., Mirkin, C.A., 2004. J. Am. Chem. Soc. 126, 5932-5933.

Nam, J.M., Thaxton, C.S., Mirkin, C.A., 2003. Science 301, 1884-1886.

Park, S.J., Taton, T.A., Mirkin, C.A., 2002. Science 295, 1503-1506.

Sun, Y., Duan, L., Guo, Z., DuanMu, Y., Ma, M., Xu, L., Zhang, Y., Gu, N., 2004. J. Magn. Magn. Mater. 285, 65-70.

Takasaki, Y., Deng, J.S., Tan, E.M., 1981. J. Exp. Med. 54, 1899-1909.

Thomas, S.M., Hopkins, M.M., Brady, M., 1998. Nat. Biotechnol. 20, $1185-1188$

Tsai, C.Y., Chang, T.L., Chen, C.C., Ko, F.H., Chen, P.H., 2005a. Microelectron. Eng. 78, 546-555.

Tsai, C.Y., Tsai, Y.H., Pun, C.C., Chan, B., Luh, T.Y., Chen, C.C., Ko, F.H., Chen, P.J., Chen, P.H., 2005b. Microsyst. Technol. 11, 91-96.

Walt, D.R., 2000. Science 287, 451-452.

Wang, J., Kawde, A., Erdem, A., Salazar, M., 2001. Analyst 126, 2020-2024. 